\title{
A Final Examination in the Language Laboratory
}

\section{Evelyn Ubrban Irving}

Present-day textbooks for teaching a foreign language and teachers of foreign languages generally are committed to teach the student to speak and understand the language when spoken. Likewise, there is general agreement that the student should be tested on what he is taught. However, frequently - or commonly - audio-lingual achievement, if tested at all, is tested by the paper and pencil method, thus testing comprehension and other facets of language, but not the ability to communicate. Generally, the excuse given for not testing speaking as well is that it is impossible to grade this aspect objectively.

It seems clear that rather than drifting into a lethargic attitude concerning this matter, it is imperative that we constantly seek methods of testing students in all phases, including speaking, and that we utilize and devise further techniques which will give as objective an evaluation of the student as possible. The author of this article has been especially concerned with this area of language testing, and in order to stimulate discussion, is presenting the form and manner of testing two hundred first-year university students of Spanish in the language laboratory at the end of the first semester. The procedure is not unique nor overlysophisticated; however, it met with sufficient success so that it seems worth reporting.

It was first decided that $15 \%$ of the final examination grade was a realistic percentage to be assigned to the oral portion; the following semester with added experience and different types of questions the percentage was increased to $25 \%$. Three types of questions in Spanish were prepared and taped by the staff under the direction of the coordinator: a dictation, a passage to be read by the student, and oral questions to be answered in Spanish. Each type of question tested different skills - the dictation, the ability to comprehend and spell; the reading passage, primarily pronunciation, intonation and fuency; the questions, ability to communicate.

The entire examination was administered in the language laboratory to groups of thirty students during their last laboratory class of the semester; there were seven groups. The examination required approximately thirty minutes since care was taken to allow the students sufficient time between parts to relax. Since each student during the semester had spent two fifty-minute periods per week in the language laboratory in 
a class situation with occasional testing, the experience was not entirely new to him. Several items necessary to proper tape preparation were observed: the recording was done with the designated instructor and a technician present so that both the linguistic and technical aspects were checked. Three forms of each question type were prepared and assigned to the classes in such a way that no student heard his own instructor's voice; at the same time a combination of native versus non-native speakers and male versus female voices was maintained. We were fortunate to be able to work out such combinations, including representatives of both Castilian and Latin American pronunciation.

All required materials were prepared on tape beforehand and presented in a laboratory equipped with individual student record positions. The dictation tape was made with pauses, the length of which had been established by one instructor writing as the person voicing the tape presented it for recording. Each sentence was read first at normal speed, then broken down into meaningful units for the student to write, and finally repeated at normal speed; thus the student heard the dictation three times. For the reading section of one hundred words, the students were allowed two minutes to prepare the selection, making any notes they wished on the paper. At a signal they were told to begin reading orally and were recorded. For the questions, each question was repeated (by a different voice) and then a pause (built into the tape) was allowed for the answer; the cue for the answer was "conteste!."

The technical aspects of the administration of examination might be of interest. The laboratory technician handled the playing of the tapes and the recording of student responses, while the instructor indicated, when necessary, the operations to be performed. The dictation tape needed only to be played. The tape for reading was a "simple" matter of recording the simultaneous responses of the thirty students. for the questions and answers, the student recorders were in operation only while the students were responding, thus eliminating the tediousness and time of listening to the questions when grading the tapes.

After each laboratory examination, the laboratory technician recorded each student tape, in turn, onto a single reel. This procedure saved many hours of work for the instructors, for not only did he cut out all silences (varying in length with the individual student) but he also levelled the volume of the students and thus produced a tape of equal volume and with a minimum of time required by the grading team. 
The student seating chart made at the time of the examination determined the order of student recordings. These recordings had been carefully identified by number at the time they were made. The seating chart provided a check on students as well as equipment, and also allowed the grading team to locate the student's paper in advance of hearing his recording - thus saving time.

In order to grade objectively, we set up criteria and a scheme of values that were a composite of our own ideas and those of several authorities on foreign languages testing - Stack, Lado, Valette, et al. We then scored in teams of two instructors who simultaneously evaluated each student.

Generally there was no disagreement in the grading, but if such arose, it was discussed immediately before proceeding to the next question. Let it be said here, that this is one advantage of recorded test answers rather than "live" ones; there is time for evaluation of a reply and opportunity to "repeat" the answer without changing the reply. The possibility of major discrepancy in arriving at a grade was slight since the entire oral examination counted only $15 \%$ and each section, $5 \%$. To achieve the objectivity aimed at in the oral examination by having no student hear his own professor's voice, no instructor graded his own students. Also, no two people functioned as a team more than once in grading tapes; therefore, there was a continuous rotation of personnel and thus more uniformity in overall marking.

As indicated previously, this article does not purport to present an ideal oral examination. Neither does the writer claim that any institution can do it; on the other hand, many institutions do it much better. In the December, 1968, issue of the NALLD Newsletter, in a "Letter to the Editor," Frank M. Grittner comments on the research of Philip Smith and while praising it, closes his letter with the comment, "would not the next step be to investigate what the laboratory can do that cannot be done by less sophisticated equipment?" It is hoped by the editor of this article that in the same vein, others will write concerning what can be done with testing in the language laboratory.

ABOUT THE AUTHOR: Dr. Evelyn Uhrhan Irving is a Sessional Professor of Spanish, Department of Languages, University of Guelph, Ontario. 